\title{
INCREASED URINARY 8-OXO-7,8-DIHYDRO-2'-DEOXYGUANOSINE EXCRETION IN A SAMPLE OF EGYPTIAN CHILDREN WITH BETA THALASSEMIA MAJOR: MARKER FOR LIPID PEROXIDATION-INDUCED DNA DAMAGE
}

\author{
MONA A ELABD ${ }^{1 *}$, DINA ABU ZEID ${ }^{1}$, MARWA A ELHADY ${ }^{2}$, MAGED A. EL WAKEEL ${ }^{1}$, GHADA M. EL-KASSAS ${ }^{1}$, \\ RANIA N SABRY ${ }^{1}$, EMAN AWADALLAH ${ }^{3}$
}

${ }^{1}$ Department of Child Health, National Research Centre, Cairo, Egypt. ${ }^{2}$ Department of Pediatrics, Faculty of Medicine, Cairo University, Cairo, Egypt. ${ }^{3}$ Department of Clinical and Chemical Pathology, National Research Centre, Cairo, Egypt. Email: mona_elabd@yahoo.com

Received: 30 June 2017, Revised and Accepted: 24 August 2017

\section{ABSTRACT}

Objective: The objective of this research was to evaluate oxidative stress status in children with $\beta$-thalassemia major.

Methods: Our study was conducted in children with $\beta$-thalassemia aged from 5 to 15 years. Investigate the urinary excretion of human 8-oxo-7,8dihydro-2'-deoxyguanosine, which will be analyzed by enzyme-linked immunosorbent assay. To investigate serum levels of antioxidant enzymes include glutathione s-transferase (GST) and catalase (CAT).

Results: We found a significant elevation of the urinary 8-oxo-7,8-dihydro- 2 '-deoxyguanosine level with p=0.001 compared to control group, a significant reduction of both GST and CAT p=0.05 and 0.03 , respectively, compared to control group. There was a significant negative correlation between urinary 8-oxo-7,8-dihydro-2'-deoxyguanisine and CAT level, $r=-0.378, p=0.016$, hemoglobin $-r=-0.610$, $p=0.001$, hematocrit $(\%)-r=-0.478$, $\mathrm{p}=0.002$, while a significant positive correlation between urinary 8-oxo-7,8-dihydro- $2^{\prime}$-deoxyguanisine and alanine aminotransferase - $\mathrm{r}=0.547$, $\mathrm{p}=0.001$, and serum ferritin $-\mathrm{r}=0.391, \mathrm{p}=0.013$. There was a significant negative correlation between CAT and serum ferritin $-r=-0.320$, $p=0.44$.

Conclusion: We conclude that the strongly increased urinary excretion 8-oxo-7,8=dihydro-2'-deoxyguanisine indicates elevated lipid peroxidation induced DNA damage in internal organs such as the liver. These highly pro mutagenic lesions may contribute to the increased risk of thalassemia patients to develop hepatocellular carcinoma.

Keywords: Thalassemia major, Children, oxidative stress, Oxidative DNA damage.

(C) 2017 The Authors. Published by Innovare Academic Sciences Pvt Ltd. This is an open access article under the CC BY license (http://creativecommons. org/licenses/by/4. 0/) DOI: http://dx.doi.org/10.22159/ajpcr.2017.v10i12.21045

\section{INTRODUCTION}

Thalassemia is a major health problem in different countries of Mediterranean origin. It's an autosomal recessive genetic disorder caused by mutations in globin chains or their regulatory regions, between the two types of thalassemia, $\beta$-thalassemia is a heterozygous state resulted from several abnormalities in the $\beta$-globin gene [1]. Hemoglobin $(\mathrm{Hb})$ appeared when there is defect in the $\beta$-globin chain in the form of glutamic acid replacement by lysine. Reduced synthesis of the $\beta E$-globin chain is due to an abnormal gene, resulting in the formulation of a mild $\beta$-thalassemia phenotype [2]. Iron overload is a significant secondary complication that happens in this type of patients, defined as an increase of serum iron saturation of transferrin (the iron-carrier protein), and ferritin (an iron-storage protein). Long-term transfusion therapy to correct anemia leads to toxic iron overload [3]. The excess iron is accumulated as ferritin and hemosiderin in many different organs such as liver and spleen. The deposited iron leads to the production of reactive oxygen species (ROS) like superoxide anion $\left(\mathrm{O}^{2-}\right)$, which via fenton reaction induces oxidative stress state. Super oxide reacts with nitric oxide radical and forms peroxynitrate resulting in oxidative stress and cellular damage in cellular acids, proteins, lipids, and carbohydrates as shown in Fig. 1 [4].

This reaction is resulting in oxidative stress, which leads to destruction in carbohydrates, lipids, proteins, and cellular nucleic acids [5]. The lipid peroxidation (LPO) process is a consequence of hydroxyl radicals, with special concern to polyunsaturated fatty acids, causing the production of many bio molecules as malondialdehyde,trans-4-hydroxy-2-nonenal, which is considered to be a chief LPO-product in vivo. It also can be oxidized by fatty acid hydro peroxides or hydrogen peroxide to originate its epoxide intermediate, it could assault the nitrogen atom in DNA bases and/or deoxyribonucleoside pool to produce the etheno ring in cytidine and adenosine causing 3,N4-ethenodeoxycytidine ( $(\varepsilon \mathrm{dC})$ and 1,N6-ethenodeoxyadenosine $(\varepsilon \mathrm{dA})$, respectively $[6,7]$. The purpose of our study was to determine the urinary excretion of human urinary 8-oxo-7,8-dihydro- 2 '-deoxyguanosine, resulting from cellular oxidative stress urinary 8-oxo-7,8-dihydro-2'-deoxyguanosine will be analyzed by enzyme-linked immunosorbent assay (ELISA). Furthermore, we want to investigate serum levels of antioxidant enzymes including glutathione-s-transferase (GST) and catalase (CAT).

\section{MATERIALS AND METHODS}

\section{Materials}

The present study conducted on 40 children with thalassemia major, of both sexes, aged 5-15 years, with stable clinical state, no acute or chronic infections, with no acute cardiovascular complications (including uncontrolled hypertension and acute heart failure). Congenital heart disease and acquired heart disease not related to the condition. Children were enrolled from the Hematology Clinic, Abo El-Reash Children Hospital, Cairo University. 40 apparently healthy children of similar age and sex recruited from the Outpatient Clinic, Children's Hospital, Cairo University. The study had been approved by the Medical Research Ethical Committee of National Research Centre.

An informed parental consent was obtained from every case before the study. Each child subjected for full medical history including duration of the disease, treatment parameters for every case including chelation 
therapy (dose, age of start, complications, and compliance). Blood transfusion frequency clinical examination, assessment of growth through measurements of weight and height. Weight for age, height for age, and body mass index (BMI) for age will be calculated according to Z scores software.

\section{Laboratory investigations}

Complete blood count, serum ferritin, kidney functions (urea and creatinine), and liver functions (alanine aminotransferase [ALT] and aspartate aminotransferase). Urinary excretion of 8-oxo-7,8-dihydro-2'deoxyguanosine will be analyzed by ELISA. Serum levels of antioxidant enzymes including glutathione (GSH), CAT, labs analyzed in Egyptian National Research Center.

\section{Biochemical markers}

Venous blood samples after an $8 \mathrm{hrs}$ fasting were collected from each subject in a sterile plain vacutainer tubes, blood on the plain tubes was allowed to clot for 30 minutes and then centrifuged at $3000 \times \mathrm{g}$ for 10 minutes at $4^{\circ} \mathrm{C}$, then the serum was separated and assayed for biochemical markers. For ELISA assay, aliquots were frozen at $-20^{\circ} \mathrm{C}$ till the time of assay to avoid erroneous results from repeated freeze/ thaw cycles.

Early morning urine samples were collected, centrifuged at $3000 \times \mathrm{g}$ for 10 minutes and then the supernatant was stored at $-20^{\circ} \mathrm{C}$ till creatinine measurement. Creatinine in urine was measured on spectrophotometer (Bio Systems BTS-302) using BIODIAGNOSTIC kit (colorimetric kinetic method).

Human 8-oxo-7,8-dihydro-2'-deoxyguanosine was assayed in urine using human 8-oxo-7,8-dihydro-2'-deoxyguanosine ELISA kit, Kono Biotech Co., Ltd. The result was expressed as a ratio to urinary creatinine to correct the variation in urinary flow.

Serum CAT was assayed using biodiagnostic colorimetric method (Cat. No. CA 25 17), the reading was on spectrophotometer (Bio Systems BTS-302).

Serum GST was performed on spectrophotometer (BioSystems BTS-302) using biodiagnostic ultraviolet method (Cat. No. GT 25 19).

\section{Statistical analysis}

SPSS 16.0 software was used in the performance of all statistical analysis. Normality of variables was evaluated by the Shapiro-Wilk test. Nonnormal variables were compared with non-parametric ways that are the Mann-Whitney U. Normal variables were analyzed using parametric methods, that is the Student's t-test. Simple linear correlation (Pearson correlation) for normal variables and Spearman's correlation for nonnormal variables were also done. $p$ value was considered statistically significant when $\mathrm{p}<0.05$ and considered statistically highly significant when its value was $<0.01$.

\section{RESULTS}

Our study subjects mean age for thalassemia patients is mean \pm standard deviation $(10 \pm 3.8)$ and for control group $(11 \pm 2.2)$, there is a significant difference between patients and control in $\mathrm{Hb}$ level and hematocrit (\%) with $\mathrm{p}=0.001$. Furthermore, patients had higher levels of ferritin as shown in Table 1 with $\mathrm{p}=0.001$. Our study subjects had the difference between patients and controls in height, weight with $\mathrm{p}=0.001$ and BMI with $\mathrm{p}=0.033$ as shown in Table 2. In this study, we measured the oxidative stress in $\beta$-thalassemia major patients through estimation of serum levels of GST, CAT, and urinary level of human 8-oxo-7,8-dihydro$2^{\prime}$-deoxyguanosine. Mean serum concentrations of GST, CAT, urinary 8-oxo-7,8-dihydro-2'deoxyguanisine, standard error in $\beta$-thalassemia major patients and controls are shown in Table 3 . We noted a significant elevation of urinary 8-oxo-7,8-dihydro-2'-deoxyguanosine level in patients than control with $\mathrm{p}=0.001$ as shown in Fig. 2 and a significant reduction of both GST (Fig. 3) and CAT in patients than
Table 1: Hematological data of $\beta$-thalassemia major patients and the control group

\begin{tabular}{llll}
\hline Variable & $\begin{array}{l}\text { Thalassemia } \\
\text { major group }\end{array}$ & Control group & p value \\
\hline Hb g/dl & $7.1 \pm 1.49$ & $12.2 \pm 0.55$ & 0.001 \\
Hematocrit $(\%)$ & $21.5 \pm 5.37$ & $36.2 \pm 7.49$ & 0.001 \\
Ferritin $\mu \mathrm{g} / \mathrm{L}$ & $2503.9 \pm 1606.9$ & $90.8 \pm 33.3$ & 0.001 \\
\hline
\end{tabular}

Results expressed as mean \pm SD. Sample size 40 patients and 40 control group. Hb: Hemoglobin, SD: Standard deviation

Table 2: Anthropometric parameters

\begin{tabular}{llll}
\hline Variable & $\begin{array}{l}\text { Thalassemia } \\
\text { major group }\end{array}$ & Control group & p value \\
\hline Weight Z score & $0.212(-1.68 \pm 1.34)$ & $0.233(-0.52 \pm 1.47)$ & 0.001 \\
Height Z score & $0.211(-1.76 \pm 1.33)$ & $0.251(-0.64 \pm 1.58)$ & 0.001 \\
BMI Z score & $0.156(-0.47 \pm 0.99)$ & $0.186(0.05 \pm 1.18)$ & 0.033 \\
\hline
\end{tabular}

Results expressed as mean \pm SD. SEM sample size 40 patients and 40 control group, BMI: Body mass index, SD: Standard deviation

Table 3: Levels of urinary human

8-oxo-7,8-dihydro-2'-deoxyguanosine, serum GST, serum CAT in $\beta$-thalassemia major patients and the control group

\begin{tabular}{llll}
\hline Variable & $\begin{array}{l}\text { Thalassemia } \\
\text { major group }\end{array}$ & Control group & p value \\
\hline $\begin{array}{l}\text { Human 8-oxo/ } \\
\text { creatinine/mg Cr }\end{array}$ & $1485 \pm 207.4$ & $203 \pm 16$ & 0.001 \\
$\begin{array}{l}\text { GST U/L } \\
\text { CAT U/L }\end{array}$ & $773 \pm 73.5$ & $1265.5 \pm 157.5$ & 0.05 \\
\hline
\end{tabular}

Results expressed as mean \pm SE. Sample size 40 patients and 40 control group CAT: Catalase, GST: Glutathione-s-transferase, SE: Standard error

controls $\mathrm{p}=0.05,0.03$, respectively. We found also a significant negative correlation between urinary 8-oxo-7,8-dihydro- $2^{\prime}$-deoxyguanosine and CAT level $-\mathrm{r}=-0.378, \mathrm{p}=0.016, \mathrm{Hb}-\mathrm{r}=-0.610, \mathrm{p}=0.001$, hematocrit $(\%)-r=-0.478, p=0.002$, and significant positive correlation between urinary 8-oxo-7,8-dihydro-2'-deoxyguanosine and ALT - $r=0.547$, $\mathrm{p}=0.001$, and serum ferritin $-\mathrm{r}=0.391, \mathrm{p}=0.013$ as shown in Fig. 4 . Furthermore, there is a significant negative correlation between CAT and serum ferritin $-\mathrm{r}=-0.320, \mathrm{p}=0.44$.

\section{DISCUSSION}

In this study, $\beta$-thalassemia major patients with oxidative stress were investigated through evaluation of the urinary excretion of human 8-oxo-7,8-dihydro-2'-deoxyguanosine and serum levels of antioxidant enzymes including CAT and GST. As expected in our study, we found significant growth retardation in patients with $\beta$-thalassemia major compared to control $(\mathrm{p}<0.05)$, this result is in agreement with many studies [8-10], chronic tissue hypoxia and iron toxicity from transfusion hemosiderosis have been implicated as major causes of retardation [11], also short stature and skeletal dysplasia can be induced by injudicious use of desferroxamine [12,13]. In our study, we found significant reduction of serum GST and CAT in beta thalassemia patients than control where GST level was (773 \pm 73.5$)$, CAT level $(410 \pm 16.1)$ in patients while GST was $(1265.5 \pm 157.5)$ and CAT was $(482 \pm 23.9)$ in control with $\mathrm{p}=0.05,0.03$, respectively, this result is in agreement with Mahdi, 2014 who found that serum level of GSH reductase, superoxide dismutase (SOD), CAT, and GSH peroxidase (GPX) decreased in thalassemia patients as compared to normal control [14]. Antioxidants are preservative agents which inactivate ROS and protect the cells from the oxidative damage, they are, for example, enzymes (SOD, GPX, and CAT) [8]. Zohaib, 2016 found that the enzymatic antioxidants activities for GSH reductase, GPX, and CAT were extremely reduced in untreated $\beta$-thalassemia patients [15]. On the other hand 


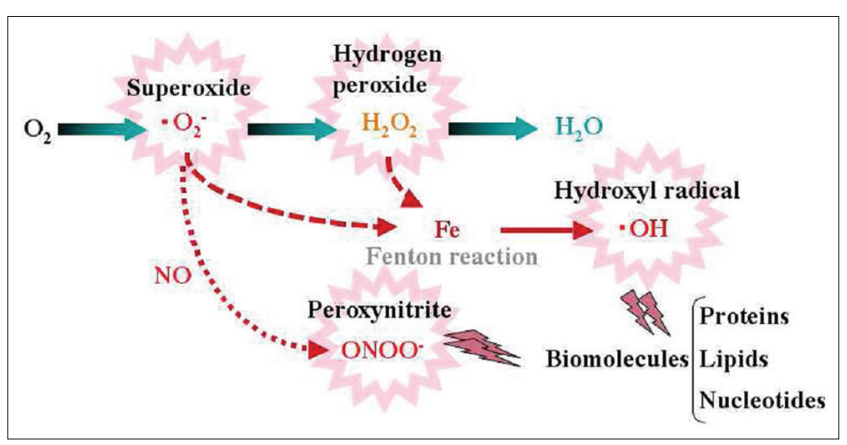

Fig. 1: Scheme elucidate the Fenton reaction

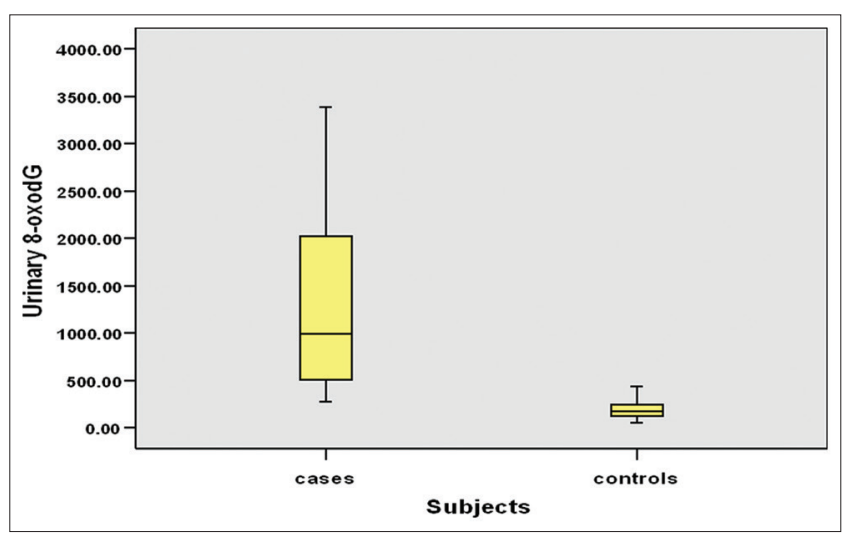

Fig. 2: Urinary 8-oxo-7,8-dihydro-2'-deoxyguanosine levels in studied subjects

when it compared to normal subjects the activity of SOD was increased in untreated thalassemia patients. Severe oxidative stress condition in the erythrocytes of the untreated transfusion dependent $\beta$-thalassemia patients is known through increase in SOD and decrease in CAT activity [16]. However, our result differs from Shazia et al., 2015 who found that serum CAT and GST are increased in $\beta$-thalassemia patients than control $(5.84 \pm 2.17 \mathrm{nmol} / \mathrm{mg}$ protein and $(86.25 \pm 15.1)$ while in healthy control $(4.76 \pm 5.2)$ and $(31.97 \pm 7.12 \mathrm{nmol} / \mathrm{mg}$ protein $) \mathrm{p}<0.05$. As a compensatory mechanism in response to oxidative stress, there's increased CAT activity while cellular damage is indicated from increased GST and LPO levels [17]. LPO end products produce miscoding etheno adducts in DNA which are excreted in urine after their repair. In our study, the urinary levels of 8-oxo-7,8-dihydro-2'deoxyguanisin were significantly increased in $\beta$-thalassemia patients Meerang et al., 2008 found that $1, \mathrm{~N} 6-\varepsilon \mathrm{dA}$ and $3, \mathrm{~N} 4-\varepsilon \mathrm{dC}$ were also significantly increased in the urine of $\beta$-thalassemia patients. $\varepsilon \mathrm{dA}$ and $\varepsilon \mathrm{dC}$ levels were assayed in collected urine samples by immune precipitation - high-performance liquid chromatography - fluorescence and 32P-postlabeling thin layer chromatography, respectively. Mean $\varepsilon \mathrm{dA}(\mathrm{fmol} / \mu \mathrm{mol}$ creatinine) levels in the urine of $\beta$-Thal/Hb E patients were found to be 8.7 times higher compared to controls. $\varepsilon \mathrm{dC}$ levels were increased 13 times over [18]. In our study, there is a significant positive correlation between urinary 8-oxo-7,8-dihydro-2'deoxyguanisine and serum ferritin $r=0.391$ ) $\mathrm{p}=0.013$ and ferritin levels correlated inversely with CAT $-\mathrm{r}=-0.320$, $p=0.44$, showing the role of excess iron in producing free radicals and the consequent tissue injury and DNA damage, this result is agreement with study by El-Gindi et al. 2015 [18]. Meerang et al., 2008 found that urinary $\varepsilon \mathrm{dC}$ levels were correlated positively with non-transferrin bound iron (NTBI) levels $(\mathrm{r}=0.517 ; \mathrm{p}=0.002)$, while there is no significant positive correlation between urinary $\varepsilon \mathrm{dA}$ and serum NTBI $(r=0.257 ; p=0.124)$ [19]. There was no correlation between serum ferritin levels and either with urinary $\varepsilon \mathrm{dA}$ and $\varepsilon \mathrm{dC}$ or with serum NTBI. Recent studies by the magnetic resonance imaging showed that the total tissue iron does not reflected by serum ferritin alone $[20,21]$. Total body DNA adducts which are formed in any tissue in the body are

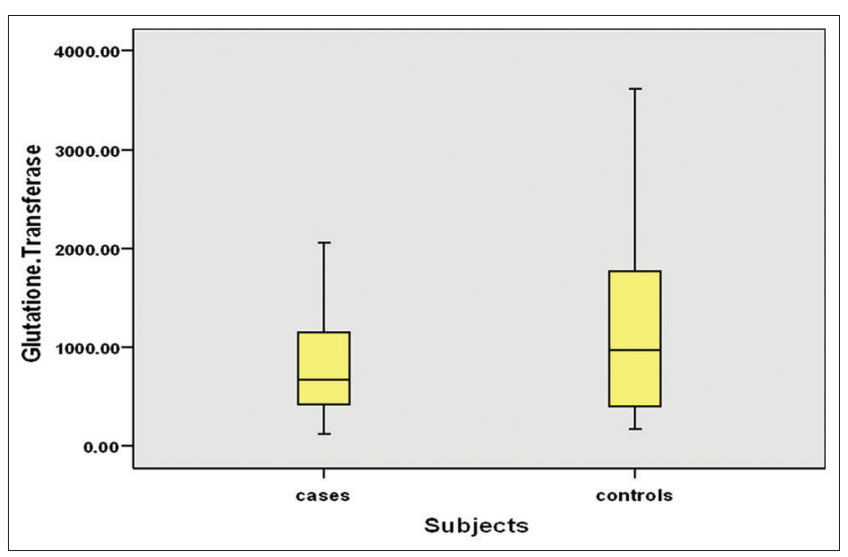

Fig. 3: Glutathione transferase levels in studied subjects

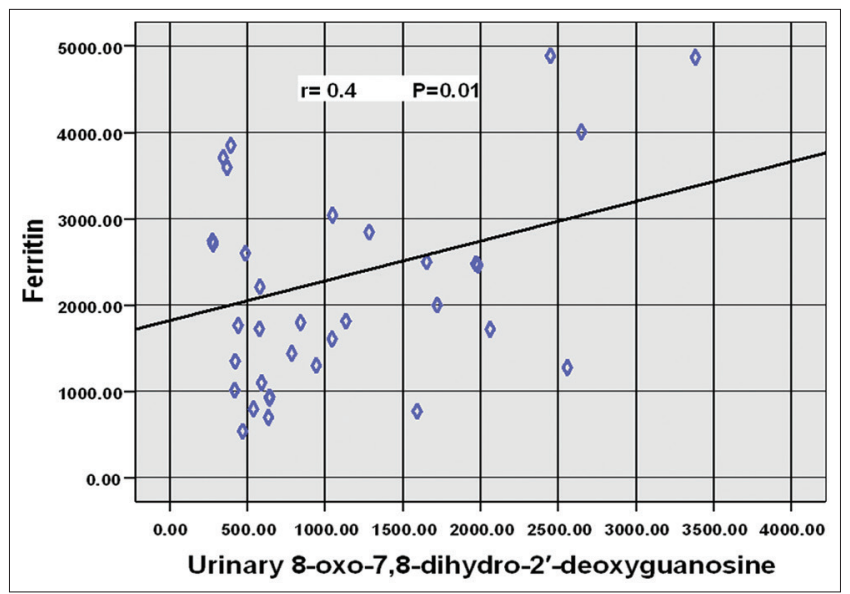

Fig. 4: Correlation between urinary 8-oxo-7,8-dihydro-2'deoxyguanosine and serum ferritin

excreted in urine after DNA repair. In addition, it is better to know the whole body iron overload than serum ferritin [22].

\section{REFERENCES}

1. Devarshi S, James S, Najafzadeh E, Pawar S, Kalrao V, Bafna V. Assessment of quality of life, complications and post-transfusion adverse reactions in thalassemia pediatric in tertiary care hospital. Int $\mathrm{J}$ Pharm PharmSci 2016;8:317-23.

2. Milena R, Branka Z, Biljana S, Belton N, Canat B. Thalassemia syndrome in Serbia. Haemoglobin 2010;34(5):477-85.

3. Biswas A, Sarkar K, Firadaus R, Saha K, Gupata D, Ghosh M, et al. Prevalence of anti-HCV, HBSAG, HIV among multi-transfused Thalassemia individuals and their socio economic background in Eastern India. Asian J Pharm Clin Res 2016;9(1):314-8.

4. Scott MD, van den Berg JJ, Repka T, Rouyer-Fessard P, Hebbel RP, Beuzard Y, et al. Effect of excess alpha-hemoglobin chains on cellular and membrane oxidation in model beta-thalassemia erythrocytes. J Clin Invest 1993;91(4):1706-2.

5. Bernhardt LK, Bairy KL, Madhyastha S. N-acetyl cysteine reverse late gestational stress induced maternal oxidative damage. Int J Pharm PharmSci 2015;7(1):165-8.

6. Walter PB, Fung EB, Killilea DW, Jiang Q, Hudes M, Madden J, et al. Oxidative stress and inflammation in iron-overloaded patients with betathalassemia or sickle cell disease. Br J Haematol 2006;135(2):254-63.

7. Kadiiska MB, Gladen BC, Baird DD, Germolec D, Graham LB, Parker CE, et al. Biomarkers of oxidative stress study II: Are oxidation products of lipids, proteins, and DNA markers of $\mathrm{CCl} 4$ poisoning? Free Radic Biol Med 2005;38:698-710.

8. Baumgartener TG. Vitamins. In: Van Way CW, editor. Nutrition Secrets. Philadelphia, PA: Hanley and Belfus; 1999. p. 13-20.

9. Dhawan V, Kumar KH, Marwaha RK, Ganguly NK. Antioxidant status in children with homozygous thalassemia. Indian Pediatr 
2005;42:1141-5

10. Simsek F, Ozturk G, Kemahl S. Oxidant and antioxidant status in beta thalassemia major patients. Ankara Universitesi Tip Fakultesi 2005;58:34-8

11. Kampa M, Nistikaki A, Tsaousis V. A new automated method for the determination of the total antioxidant capacity (TAC) of human plasma, based on the croc in bleaching assay. BMC Clin Pathol 2002;2:3-6.

12. Das N, Inas M, Datty A, Sarcar R, Deniz A. Attenuation of oxidative stress induced changes In thalassemia erythrocytes by vitamin E. Pol J Pharmacol 2014;26:85-96.

13. Chan AC, Chow CK, Chiu D. Interaction of antioxidants and their implication in genetic anemia. Proc Soc Exp Biol Med 1999;222(3):274-82

14. Mahdi EA. Relationship between oxidative stress and antioxidant status in beta thalassemia major patients. Acta Chim Pharm Indica 2014;4:137-45.

15. Zohaib M, Ansari SH, Hashim Z, Shamsi TS, Zarina S. Serum paraoxonase activity and malondialdehyde serum concentrations remain unaffected in response to hydroxyurea therapy in $\beta$-thalassemia patients. J Clin Pharmacol 2016;56:869-74.

16. Theodoridis C, Ladis V, Papatheodorou A, Berdousi H, Palamidou F, Evagelopoulou C, et al. Growth and management of short stature in thalassaemia major. J Pediatr Endocrinol Metab
1998;11 Suppl 3:835-44.

17. Shazia Q, Mohammad H, Mohammad I, Kamarudin D, Mudin D. Evaluation of antioxidant status in beta thalassemia major patients in Sabah, Malaysian Borneo. Biores Commun 2015;1(1):45-7.

18. El-Gindi HD, Hassanin AI, Mostafa NO, El-Kassas GM, El Wakeel MA, El-Batal WH, et al. Oxidative DNA damage in $\beta$-thalassemic children. Med Res J 2015;14(2):41-6.

19. Meerang M, Nair J, Sarankapracha P, Thepinlap C, Srichairatanakool S, Fucharoen S, et al. Increased urinary 1,N6-ethenodeoxyadenosine and 3,N4-ethenodeoxycytidine excretion in thalassemia patients: Markers for lipid peroxidation-induced DNA damage Free Radic Biol Med 2008;44:1863-8.

20. Christoforidis A, Haritandi A, Tsitouridis I, Tsatra I, Tsantali H, Karyda S, et al. Correlative study of iron accumulation in liver, myocardium, and pituitary assessed with MRI in young thalassemic patients. J Pediatr Hematol Oncol 2006;28:311-5.

21. Argyropoulou MI, Astrakas L. MRI evaluation of tissue iron burden in patients with beta-thalassaemia major. Pediatr Radiol 2007;37:1191-200

22. Livrea MA, Tesoriere L, Pintaudi AM, Calabrese A, Maggio A, Freisleben HJ, et al. Oxidative stress and antioxidant status in betathalassemia major: Iron overload and depletion of lipid-soluble antioxidants. Blood 1996;88:3608-14. 